Arqueología y Sociedad,

№ 20, 2009

\title{
Cuninico y Maipuco, DOS Sitios ARQUEOLÓGICOS EN EL RÍO MARAÑÓN
}

\author{
Martín Mac Kay Fulle* \\ Raphael Santa Cruz Gamarra**
}

\section{Resumen}

En el río Marañón, región Loreto, se encuentran los sitios arqueologicos de Cuninico y Maipuco. Ambos sitios, dado su contexto pueden darnos una nueva idea de la importancia y complejidad de las sociedades precolombinas existentes en las riberas del Marañón y las quebradas adyacentes hasta ya muy entrado el siglo XVI. Mientras los materiales registrados nos dan informacion de la continuidad en algunas manifestaciones culturales aun existentes en el area de las comunidades de la etnia urarina.

Palabras claves

Maipuco, Cuninico, río Marañón, río Corrientes, Loreto, Amazonía.

\begin{abstract}
In the river Marañon, region Loreto, there are the archaeological places of Cuninico and Maipuco. Both places, given his context can give us a new idea of the importance and complexity of the existing pre-Columbian societies in the banks of Marañon and the adjacent gorges even already much brought in the XVIth century. While the registered materials give us information of the continuity in some even existing cultural events in the field of the communities of the ethnic group urarina.
\end{abstract}

\section{Keywords}

Maipuco, Cuninico, river Marañón, river Corrientes, Loreto, Amazonia.

\footnotetext{
* Licenciado en Arqueologia de la PUCP, miembro ordinario del Instituto Riva Aguero y del Instituto de Estudios Historico Maritimos. Gerente Comercial de la empresa consultora ARKCOS EA.

Correo electrónico: martin.mackay@arkcos-ea.com

** Licenciado en Arqueologia de la PUCP, miembro ordinario del Instituto Riva Aguero y del Instituto de Estudios Historico Maritimos. Gerente General de la empresa consultora ARKCOS EA.

Correo electrónico: raphael.santacruz@arkcos-ea.com
} 
Con todo mi amor, para Diana Victoria

\section{INTRODUCCIÓN}

Durante los meses de diciembre de 2008 y enero del 2009, durante la realización de trabajos dentro del Proyecto de Evaluación Arqueológica del Lote 106 (departamento de Loreto, distritos de Urarinas y Trompeteros) bajo la concesión de Petrolífera Petroleum del Perú, se pudo recorrer 105 kilómetros del curso del río Marañón entre los poblados de Santa Teresa y Ollanta, en territorios de la etnia Urarinas, además de sus afluentes, los ríos Chambira y Tigrillo.

En dicho trayecto, se prospectaron ambas márgenes del río y pudimos registrar dos sitios arqueológicos ubicados en los actuales centros poblados de Cuninico y Maipuco. Ambos sitios constituyen un importante ejemplo del tipo de contexto arqueológico al que deben enfrentarse los arqueólogos en la selva baja del Perú, contextos que son destruidos por el constante movimiento del caudal fluvial de los grandes ríos, como es el caso del Marañón.

La idea central del presente este artículo es presentar ambos sitios y sus particulares características como lugares de investigación arqueológica en la selva baja, así como una breve descripción de los materiales documentados en ellos, haciendo una primera comparación con otros materiales registrados en nuestra Amazonía. Del mismo modo, se presentan los materiales encontrados por pobladores de la zona en otras localidades del curso recorrido en el Marañón y un anexo de los trabajos realizados en el río Corrientes, el cual estaba ubicado en la parte norte del ya mencionado Lote 106.

\section{ANTECEDENTES DE ESTUdIOS ARQUEOLÓGICOS EN LA AMAzonia}

La investigación arqueológica en la región de la selva tiene varias limitaciones a causa de sus características (bosque espeso, inundaciones, capa orgánica, etc.), impidiendo un adecuado registro de la evidencia arqueológica. A esto debe sumarse la mala conservación de los artefactos, fabricados en su mayoría de material orgánico es decir, de corteza de árbol, fibra vegetal, caña, hueso de animal, entre otros. Básicamente, los únicos artefactos antiguos que se conservan en esta región son aquellos hechos de cerámica y de piedra; de este modo, se han hallado vasijas de cerámica completas o fragmentadas (ollas, cántaros, platos, urnas funerarias, etc.), hachas de piedra, batanes, manos de moler, pictografías (pintura) y petroglifos (tallado) sobre piedra. Estas evidencias muchas veces aparecen dispersas, fuera de su contexto original de deposición debido a la acción de agentes naturales y humanos. Sin embargo, a pesar de estas dificultades, algunos investigadores han comenzado a reconstruir la historia de los pueblos antiguos de la Amazonía. Cabe destacar que la principal fuente de estudio es el análisis de la cerámica, que permite construir las distinciones cronológicas, étnicas y culturales correspondientes.

Las investigaciones arqueológicas abarcan diferentes cuencas de la Amazonía (Lathrap 1970; Shady 1971; Rivas 2003; Lennon et al. 1989; Myers, 1981a, 1981b; Fung 1981; Ravines 1981; De boer 1981; Lennon y Church 1989; Morales 1992; Myers y Dean 1999; Guffroy 2006; Rostain 2006). Una de las cuencas más estudiadas es la del río Ucayali (Lathrap 1970), donde se ha logrado definir varias fases de ocupación correspondientes a diferentes migraciones desde períodos tempranos, alrededor del 2000 a.C. (fase Early Tutischcainyo) hasta la llegada de los españoles (fase Cumancaya), y que ha servido de columna comparativa para estudios posteriores en otras cuencas. En la última fase denominada Cumancaya, destaca la aparición de la cerámica Corrugada, un estilo que abarca diferentes cuencas del Perú, Ecuador, Colombia y Brasil. Este estilo guarda semejanzas con la cerámica de las etnias actuales que ocupan esta región, tales como la Shipibo-Conibo perteneciente al grupo lingüístico Panoan, por lo que se piensa que fueron ancestros de este grupo. Un ejemplo de lo dicho es la cerámi- 
ca funeraria encontrada en el sitio Sonochenea (UCA-40), la cual guarda semejanzas con la cerámica de alimentos y para masato de los Conibo. Las urnas funerarias del estilo Sanochenea son fechadas alrededor del 800 al 1000 d.C.

Otro importante estilo de esta fase es la cerámica Caimito (perteneciente al estilo Polícromo) que en el Ucayali reemplaza a la cerámica Corrugada. Tiene muchas similitudes con estilos del río Napo en Ecuador y del río Gurupy de la costa de Brasil. Lathrap (1970) sostiene que la dispersión de este estilo es evidencia de las múltiples migraciones que se dieron en la Amazonía, en este caso de las migraciones tupiguaraní entre el 1100 y 1700 d.C. Como el estilo anterior, los estilos Caimito y Napo tienen estrecha relación con la cerámica de los grupos actuales de esta región del Alto Amazonas como son los Cocoma y los Omagua, quienes fueran asentándose paulatinamente tanto en la cuenca del Ucayali, como del Marañón y del Huallaga.

Sin embargo, como bien escribe Guffroy (2006), la distribución de la cerámica Corrugada en un área tan vasta como ésta -desde el río Upano (Ecuador) hasta la cuenca del río Grande en Brasil-, no puede explicarse por el desplazamiento de un solo grupo y tampoco sólo como mecanismo de difusión. Guffroy encuentra que existen, por lo menos, cuatro familias lingüísticas históricas relacionadas a este estilo, como son: Tupi-Guaraní al sur, Arawak al norte, y Jibaroan y Panoan al este. De manera paralela, el estilo Polícromo también se difunde por el Amazonas; en algunos casos ambos estilos se encuentran juntos (río Chambira) mientras que en otros (río Ucayali) la cerámica Corrugada es reemplazada por la cerámica Polícroma (Caimito).

En el extremo suroeste del departamento de Loreto, en la cuenca del río Cachiyacu, uno de los afluentes superiores del río Paranapura, se registró un grupo de asentamientos pre-hispánicos denominado Complejo Balsapuerto (Rivas 2003). En la actualidad, esta región es ocupada por la etnia Chayahuita. Esta cuenca cuenta con un importante recurso salino que permite a los Chayahuitas de los afluentes del Marañón y el Huallaga (y de otras etnias como los Aguaruna) obtener sal para su consumo en época de verano. Los sitios arqueológicos registrados se ubican, por lo general, en terrenos no inundables tales como terrazas altas y colinas bajas, a orillas del río Cachiyacu. En muchos casos, estos mismos lugares son ocupados hoy por los Chayahuitas, etnia asentada en esta zona de la selva por aproximadamente cuatro siglos. Sin embargo, los estilos cerámicos registrados en los sitios arqueológicos difieren de la cerámica de esta etnia, por lo que resulta probable que esta zona haya sido ocupada por grupos anteriores. Más bien, estos estilos cerámicos guardan relación con tradiciones como la Upano de la selva ecuatoriana, el estilo Corrugado de la fase Cumancaya de la cuenca del Ucayali, y con la cerámica de la cultura Chachapoyas de la cuenca alta del Utcubamba. Estas poblaciones del río Cachiyacu se calculan entre los 1000 al 1200 d.C. (id.), si bien los estilos anteriormente mencionados están alrededor del 800 al 1000 d.C.

En la cuenca del río Marañón, específicamente en uno de sus afluentes, el río Chambira, (al suroeste del Lote 106), se localizó cuatro agrupaciones de sitios arqueológicos denominadas por Morales (1992) como concentraciones dispersas. En base al estudio de la cerámica proveniente de estos sitios y su correlación estratigráfica (Morales, 1992) se ha propuesto cuatro fases alfareras:

Fase Chambira. La cerámica de esta fase guarda relación con la región costera ecuatorial y se ubica temporalmente en el Formativo Tardío, alrededor del 1000 a.C., contemporáneo a la fase Late Tutischcainyo de la cuenca del Ucayali.

Fase Siamba. La cerámica se relaciona al estilo Barrancoide y a la fase Hupa-Iya del Ucayali, se calcula una fecha alrededor del 200 al 300 a.C. Cabe mencionar que el estilo Barrancoide representa las migraciones ocurridas alrededor 
del 200 a.C. por grupos que tienen su origen en la Amazonía Central.

Fase Tigrillo. Presenta los estilos cerámicos Polícromo y Corrugado, fechados en la región de Ucayali entre el 700 d.C. y 1000 d.C.

Fase Urarina. Es caracterizada por la cerámica actual de la etnia Urarina que habita en esta región (Morales 1992; Myers y Dean 1999).

Otros hallazgos arqueológicos importantes son descritos para el sitio de Valencia ubicado en la cuenca del río Corrientes, afluente del río Tigre (al norte del Lote 106). Estos hallazgos consisten de vasijas funerarias y fragmentos cerámicos correspondientes posiblemente a grupos etnolingüísticos de la familia Jíbaro, aunque también cabe la posibilidad de que pertenezcan a otros grupos que fueron desplazados de la zona. El estilo cerámico funerario de Valencia guarda estrecha relación con el estilo de Sonochenea de la cuenca alta del Ucayali perteneciente a la fase Cumancaya; ambos estilos tienen impresión en uñas y pintura amarilla post-cocción en zonas.

Como se mencionara anteriormente, si bien una de las principales fuentes para el estudio arqueológico en la selva es la cerámica, no se puede descartar el estudio de otras evidencias como la arquitectónica, de características muy diferentes a las que normalmente uno pensaría encontrar en la Amazonía. Un ejemplo de lo dicho se encuentra en la cuenca del río Chinchipe, afluente del Marañón en Jaén, donde se ubicó montículos artificiales que esconden arquitectura de carácter monumental construida con cantos rodados y barro, y con paredes enlucidas con una capa de arcilla. Inclusive en la zona de la cuenca del río Utcubamba en Bagua, al pie del cerro Los Peroles, se ha encontrado arquitectura semejante con frisos polícromos. La cerámica es polícroma con incisiones y pertenece al Periodo Formativo (1200 al 800 a.C.).

En suma, en la selva se han encontrado ocupaciones muy tempranas que datan desde el 2000 a.C. aproximadamente, hasta ocupaciones posteriores a la llegada de los españoles. El estudio de los estilos cerámicos recuperados muestra indicios de diferentes migraciones de grupos que se desplazan en la Amazonía, aún no bien comprendidas, y que son ancestros en algunos casos de los grupos actuales asentados en las regiones estudiadas como los Cocoma, Urarina y Shipibo-Conibo entre otros. En otros casos, las evidencias arqueológicas señalan que se trataría de grupos distintos, desaparecidos de esas zonas. Por lo general, estos grupos humanos se asentaron en las colinas bajas y terrazas a los lados de los ríos, en áreas no inundables, distribuidos tanto en la ceja de selva, como en la selva alta y baja. Muchos de estos antiguos asentamientos hoy se encuentran bajo las comunidades nativas actuales.

\section{Cuninico}

El poblado de Cuninico se encuentra ubicado en el cruce de la quebrada del mismo nombre con el río Marañón (coordenadas UTM WGS 84-Zona 18: 0475856E/9469245N), frente a un grupo de islotes visibles sólo en algunas épocas del año cuando hay merma en el curso del río. Este poblado cuenta con casi un centenar de familias que se dedican básicamente a la agricultura de frutos, yuca y algunas hortalizas para consumo, la tala de madera y, en especial, a la pesca artesanal. Durante la primera visita al lugar, se preguntó a los pobladores de mayor edad (entre ellos el señor Diego Silva de 76 años) acerca de la existencia de restos arqueológicos en la zona. Ocasionalmente, durante las labores de sembrado y mantenimiento de sus viviendas, los pobladores mencionaron la aparición de fragmentos de cerámica antiguos; estos hallazgos eran poco comunes en el propio Cuninico en comparación a otras locaciones de la quebrada conocidas como "El Retiro" y "El Oje", ambas lugares de siembra a una hora de distancia (en peque) con dirección norte desde el centro poblado. Durante esta visita, no se pudo ver nin- 

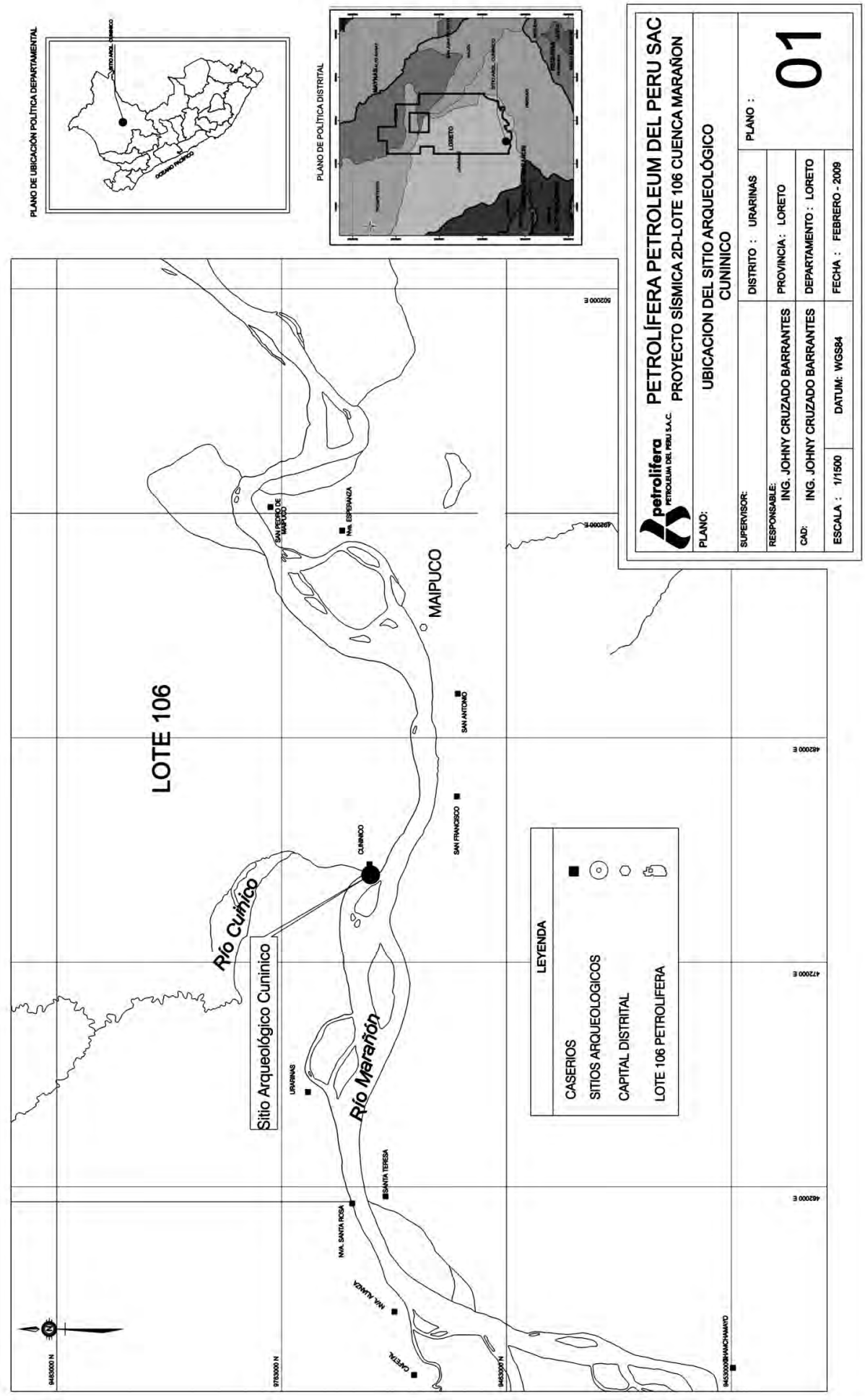

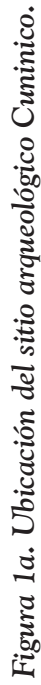



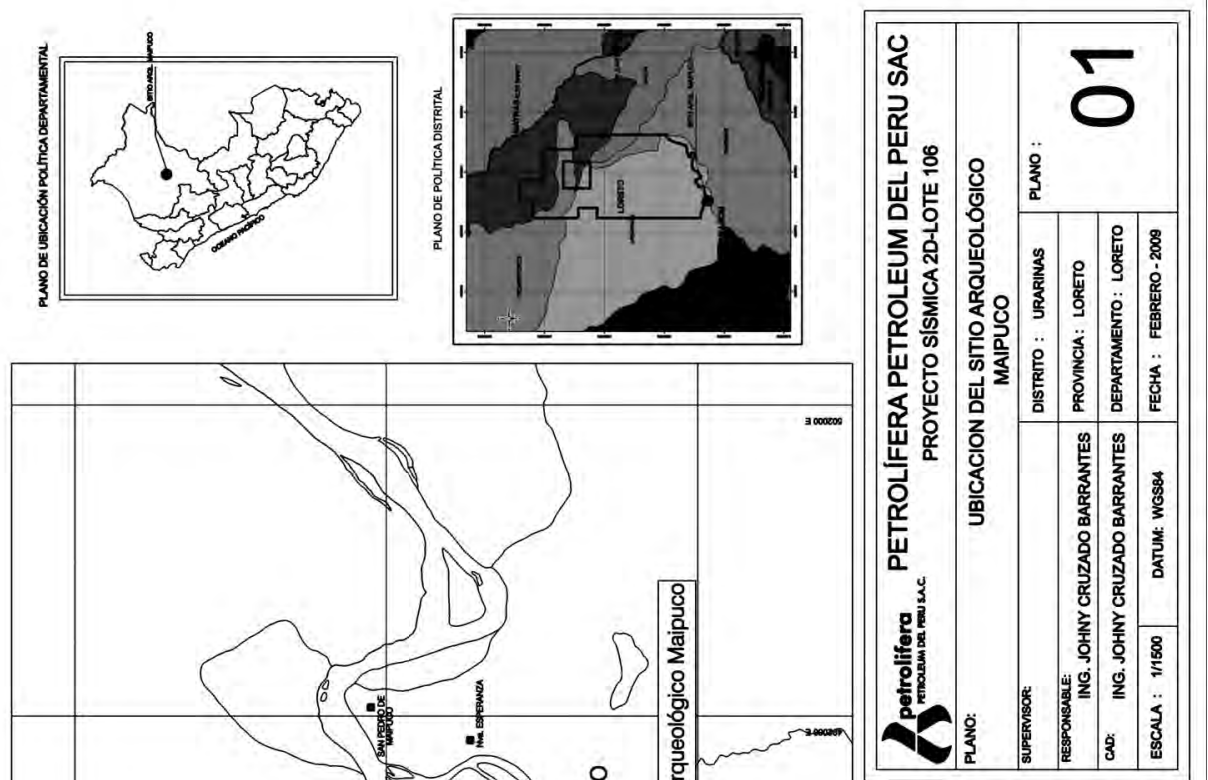

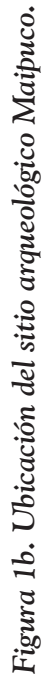




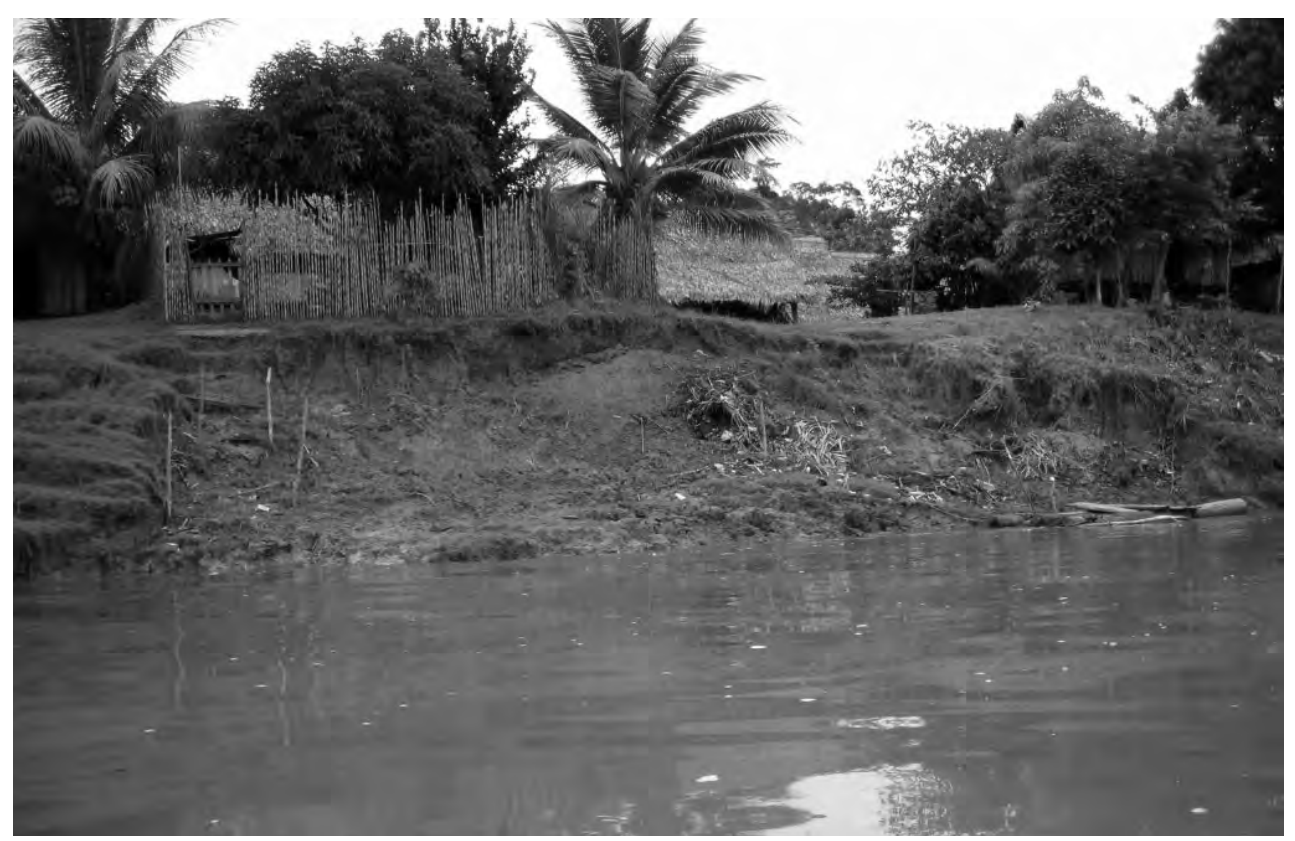

Figura 2. Cuninico a orillas del Marañón el día 9 de enero, 2009.

gún tipo de material en el terreno ni en posesión de los pobladores. Una semana después, guiados por unos niños nos trasladamos a la zona ubicada al sur del mismo poblado, a unos 5 minutos desde la parte central del mismo. Una vez en el lugar, se observó la existencia de un botadero de basura moderna entre la base de una casa y la orilla del río (coordenada UTM WGS 84-Zona 18: 0475886E/9469046N) con gran cantidad de fragmentería cerámica al interior del fango y lodo dejado tras la merma de las aguas tanto del Marañón como de la quebrada de Cuninico (fig. 2). Dentro de esta grava se pudo observar cerámica de hasta tres tipos de estilos muy bien definidos:

- Cerámica alisada y/o bruñida con decoración incisa (diseños geométricos) y luego pintada (post cocción) de color ocre. Ésta constituye prácticamente el $80 \%$ de la muestra (fig. 3).

- Cerámica alisada con engobe ocre o crema y decoración pintada ocre o crema (diseños geométricos o aves estilizadas). Esto cons- tituye un poco más del 18\% de la muestra (fig. 4).

- Cerámica alisada y/o bruñida con decoración polícroma y escultórica modelada. Esto constituye no más del $2 \%$ de la muestra (fig. 5).

Este material se hallaba en una estratigrafía que puede ser descrita de la siguiente manera: Estrato 1: superficie actual del poblado, arena húmeda y oscura, de $0.30 \mathrm{~m}$ de grosor. No presenta material cultural.

Estrato 2: grava marrón claro mezclada con arena muy húmeda, de $0.70 \mathrm{~m}$. de grosor. No presenta material cultural.

Estrato 3: grava marrón oscuro muy húmeda, entre 1.00 y $1.50 \mathrm{~m}$ de espesor. Presenta material cultural.

Estrato 4: grava gris claro muy húmeda desde $1.50 \mathrm{~m}$. hasta la orilla misma del río, a unos 3.00 m. Presenta material cultural.

Es importante mencionar que la revisión de dicho perfil y su estratigrafía fue realizada el día 9 de enero del 2009, cuando era factible revisar 


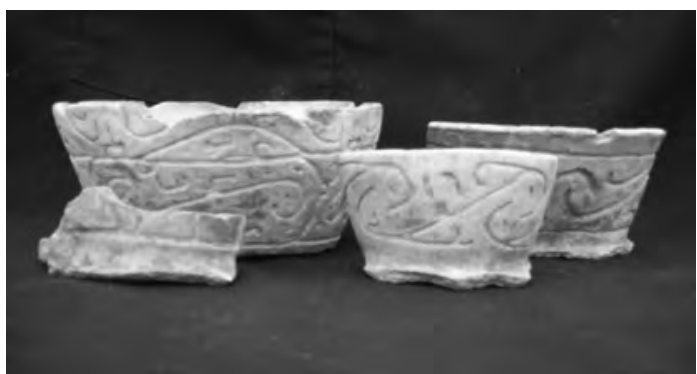

Figura 3. Cerámica bruñida y decorada con incisos (Cuninico).

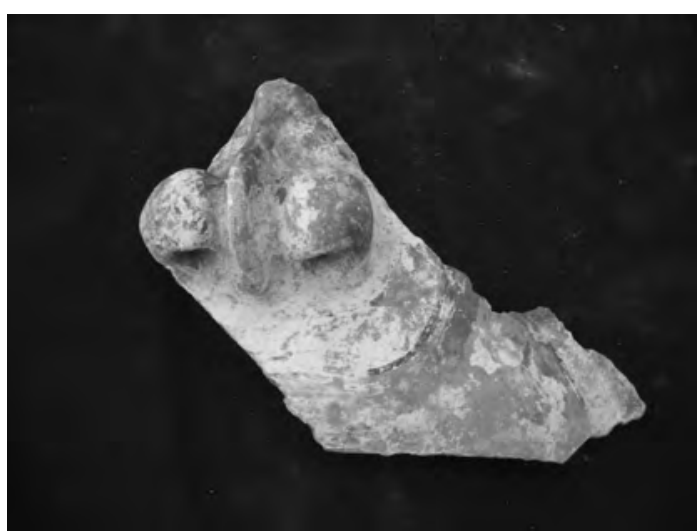

Figura 5. Cerámica escultórica pintada (Cuninico).

el material descrito (el cual posteriormente fue puesto en custodia de las autoridades de la localidad). Posteriormente, se realizaron dos visitas más al lugar de los hallazgos (12 y 15 de enero) observándose la crecida del Marañón hasta en 31 metros, como lo indica el limnímetro en su registro llevado a cabo por la empresa PGS Onshore (figs. 6 y 23). Asimismo, algunos pescadores y señoras que se dedican a lavar su ropa en las orillas cercanas, mencionan que en el cruce de los ríos Marañón y Cuninico la merma en los meses de junio y julio puede retirar el cauce desde la actual orilla unos 15 metros y bajar el caudal unos 10 metros como máximo. Esto implicaría que el sitio arqueológico de Cuninico se habría encontrado en una orilla antigua que habría colapsado, ubicándolo hoy en el cauce moderno. Otros pobladores, sobre todo niños, indicaron que cuando ocurría esta merma se podían hallar "tejas"; esto reafirmaría nuestra idea de consi-

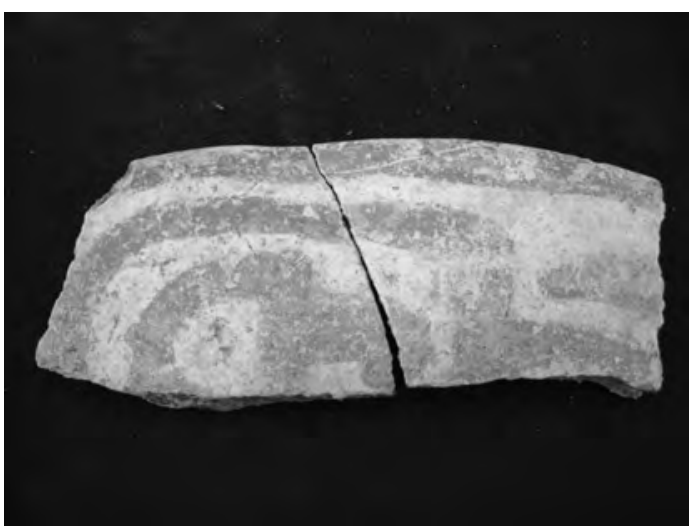

Figura 4. Cerámica alisada con decoración pintada (Cuninico).

derar el antiguo poblado de Cuninico como un sitio hundido que quizás, salvo por los meses de la merma mencionada, podría ser un lugar de estudio y trabajo por parte de arqueólogos submarinistas.

El material hallado no presenta un contexto claro. Prácticamente la totalidad del mismo (8 $\mathrm{kg}$ de fragmentos de vasija de cerámica) presenta decoración incisa, pintada, o ambas. Las formas reconocibles son platos con pedestal, cuencos y grandes vasijas para almacenar líquidos y urnas, probablemente de uso ceremonial o de uso restringido. En cuanto a la cronología de este material, los diseños incisos y algunas de las formas de los cuencos son muy similares a materiales hallados en el río Napo, fechado entre el 1000 y el 1500 d.C. como casi todos los materiales de estas características posteriores al ya mencionado estilo Corrugado de amplia difusión espacial y temporal en la Amazonia. Resulta necesario realizar una comparación de manera más exhaustiva de los materiales de Cuninico y complementar con excavaciones que arrojen información más precisa sobre la cronología y la realidad del contexto hallado. Recordemos, por ejemplo, que muchas características de la fragmentería observada en el campo son similares a las descripciones hechas por Morales para su fase Tigrillo, la cual nos haría retroceder hasta tres siglos en la cronología propuesta en un inicio. 


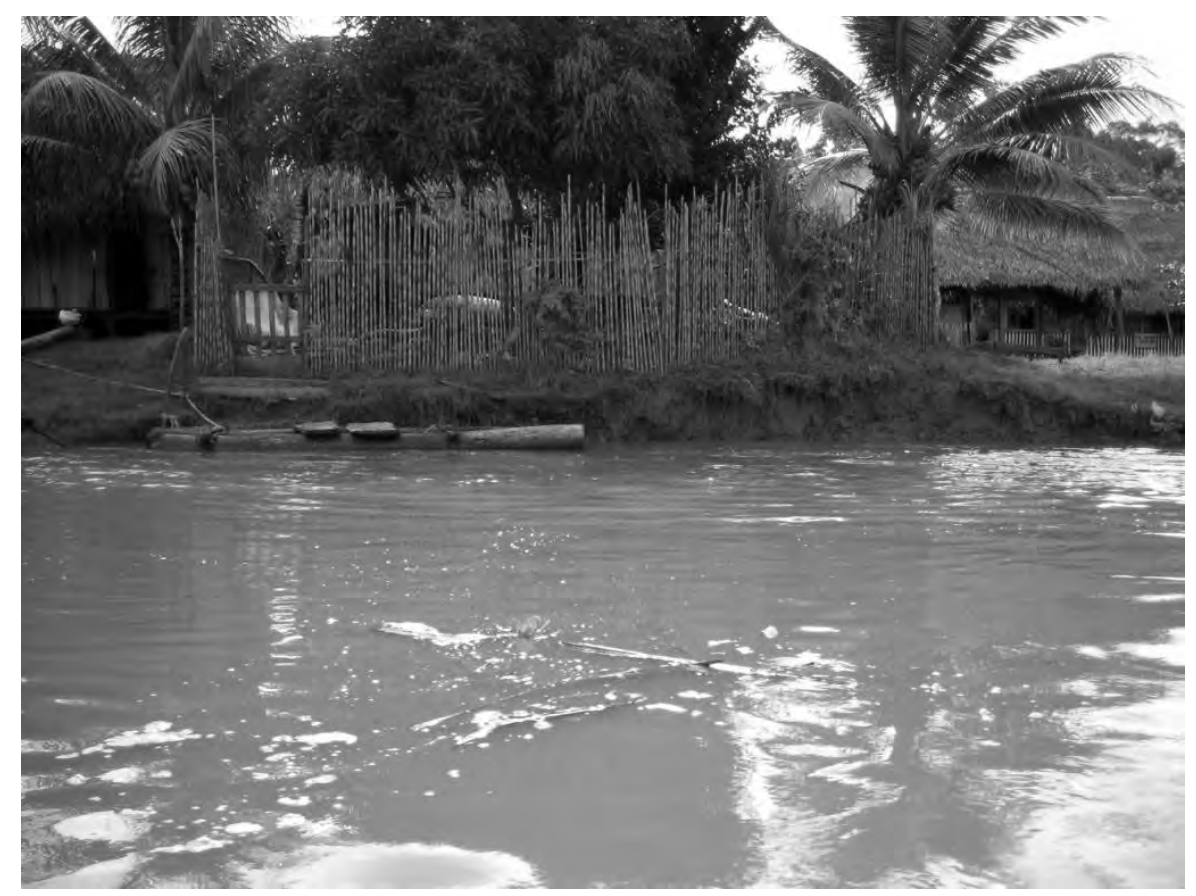

Figura 6. Cuninico a orillas del Marañón el día 15 de enero, 2009.

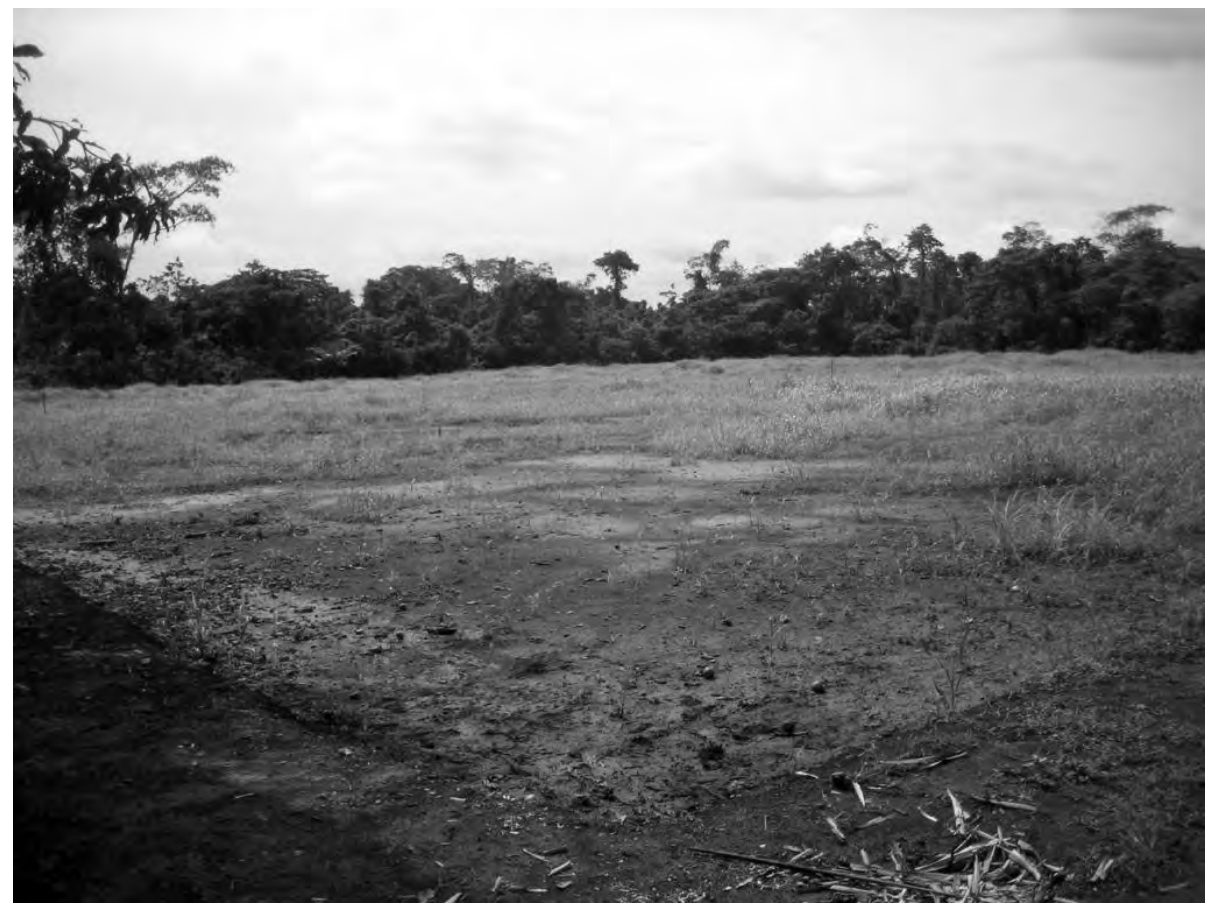

Figura 7. Área arqueológica de Maipuco. 
Las comparaciones de los hallazgos de $\mathrm{Cu}$ ninico con otros materiales registrados sistemáticamente nos llevan hasta el río Oran en el mismo departamento de Loreto, en donde Rivas Panduro y Myers (2004) describen su denominada "cerámica Oran Acalanada" y "cerámica Oran Policroma" ambas de similar manufactura y decoración a los fragmentos vistos por nuestro equipo en el Marañón. Asimismo, algunas piezas halladas por Morales en el sitio del Zapote, dentro de la Reserva Nacional de Pacaya-Samiria limítrofe a nuestra área de estudio, son similares a las de Cuninico.

Cabe mencionar que ambos autores coinciden en señalar un fechado tardío de este tipo de evidencias.

\section{MAIPUCO}

El segundo sitio arqueológico registrado durante nuestro recorrido en el Marañón, fue el localizado a las afueras de la capital del distrito de Urarinas, el centro poblado de Maipuco. Este sitio se encuentra a unos 3 kilómetros tierra adentro en dirección sur desde la zona del puerto, siguiendo en línea recta la avenida Horacio Grandez (coordenada UTM WGS 84-Zona 18:
0486656E/9466286N) (Fig. 7), detrás del Centro Cívico de Maipuco. Pobladores de Maipuco mencionaron que tras los trabajos de remoción y nivelado de tierras para la construcción del Nuevo Complejo Deportivo Municipal entre los meses de setiembre y octubre de 2008, durante estas labores aparecieron en superficie muchos fragmentos de ceramios aparentemente antiguos. El terreno de 150 metros cuadrados en mención (coordenada UTM WGS 84-Zona 18: 0486641E/9465878N) presentó gran cantidad de fragmentos cerámicos, gran parte de ellos vasijas utilitarias (ollas y cuencos) con decoración aplicada a manera de trenzas (fig. 8) y un número importante de husos textiles o piruros hechos de arcilla (fig. 9). Se trataba, indudablemente, de una gran cantidad de material que conformaba una muestra muy homogénea en estilo y formas. Esto se podía observar tanto en el material observado en superficie como en los perfiles que no sobrepasaban los $0.30 \mathrm{~m}$ de profundidad.

Gracias al apoyo de la dotación policial local, se pudo registrar los materiales en superficie así como hacer el registro gráfico de algunas piezas que habían salido del lugar (fig. 10). Por medio de entrevistas realizadas a vecinos y per-

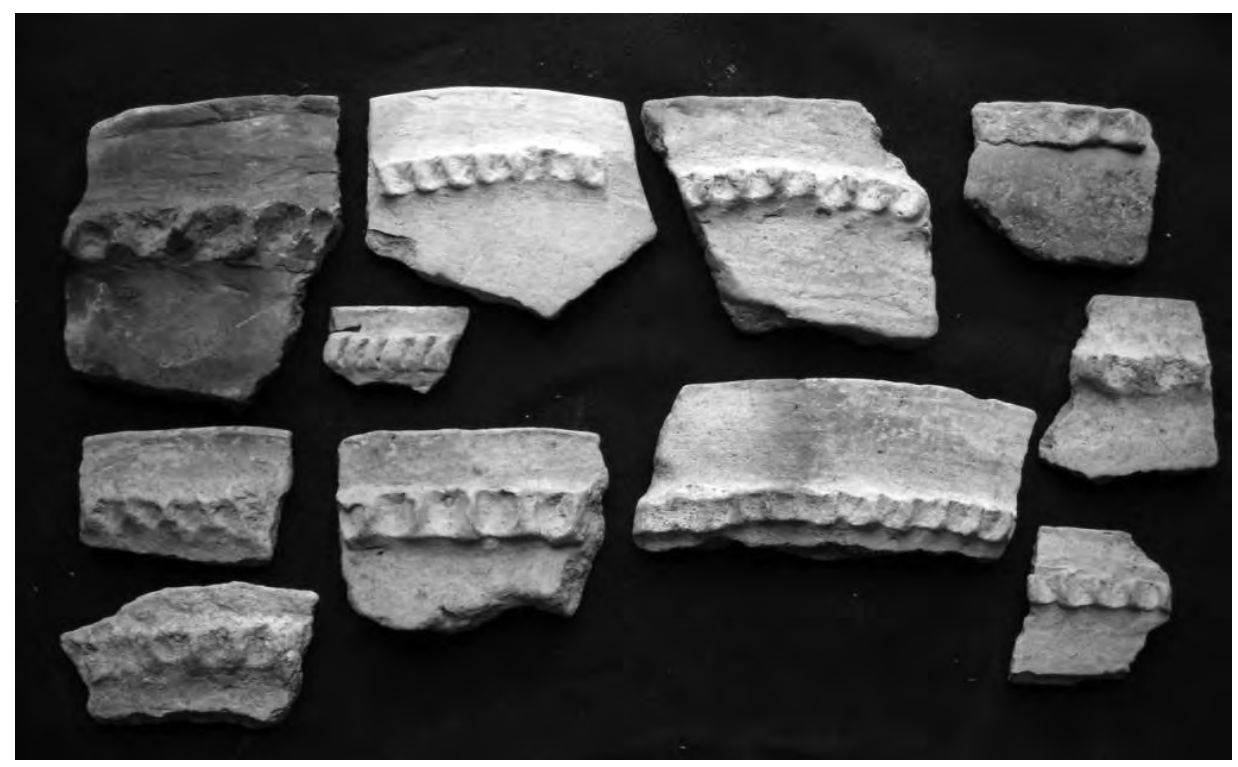

Figura 8. Cerámica con decoración aplicada (Maipuco). 


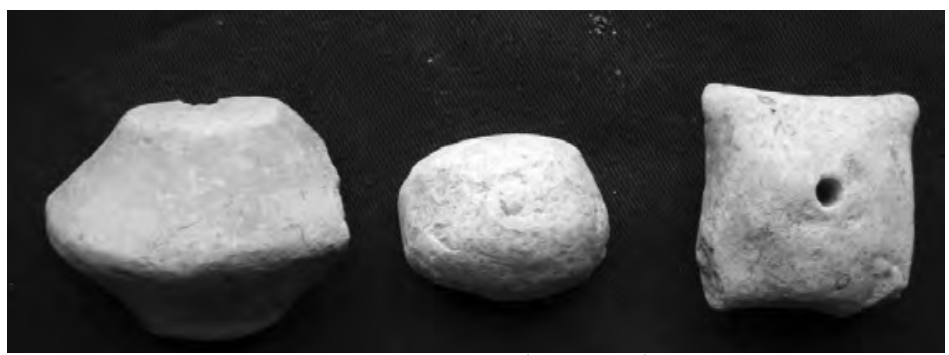

Figura 9. Piruros (Maipuco).

sonas presentes durante la nivelación del terreno pudimos conocer de la existencia previa de "una colinita de forma regular, de unos $30 \mathrm{~m}$ de largo y unos $3 \mathrm{~m}$ de alto ubicada al extremo sureste del lugar de donde aparecieron muchas ollitas enteras". Esta información revelaría la posible existencia de una estructura prehispánica. Este sitio arqueológico habría tenido una ubicación privilegiada, pues al ubicarse lejos de las orillas del Marañón se encontraba protegido de los constates derrumbes del perfil del río. Adicionalmente, ésta es una posición estratégica puesto que el sitio se ubicaba en la intersección de muchos puntos clave para la supervivencia de la población, tales como ciertas cochas y las quebradas del Pinche y Yanayacu, (las cuales dan acceso a la Reserva de Pacaya-Samiria) y el paso a conexiones que unen el Marañón con el Ucayali y la zona de la actual ciudad de Yurimaguas.

Figura 10. Ceramio encontrado durante las obras de campo deportivo en Maipuco. La vasija ha sido pintada por miembros de una Iglesia Evangélica local.
Según la Lic. Isabel Jiménez, arqueóloga del INC de Iquitos, el tipo de decoración existente en Maipuco -de aplicados en forma de trenza- es una típica forma decorativa de épocas prehispánicas tardías (1000 a 1500 d.C.) por lo cual dicha muestra era posiblemente contemporánea a lo antes observado en Cuninico. además de las formas utilitarias como ollas y cuencos, los aplicados en forma de trenza y los piruros ya mencionados, podemos agregar que el acabado de dichas piezas era básicamente alisado con algunos pocos ejemplos de bruñidos. Asimismo, se halló otros dos tipos de decoración pero en menor frecuencia, a saber, los aplicados en forma de serpiente y algunos incisos muy burdos, así como también algunos fragmentos hechos en base a la técnica de la manufactura por anillado.

Gran parte del material tenía huellas de uso por cocción.

\section{Otros MATERIAles} queológicos descritos, durante la prospección en los $105 \mathrm{ki}$ lómetros en ambas orillas del Marañón y los ríos Chambira y Tigrillo se pudo registrar algunos materiales recuperados por los pobladores de varias comunidades ribereñas durante la remoción de tierras para la siembra y de los trabajos de refacción de sus hogares. Estos materiales descontextualizados son de utilidad para compararlos con los ya observados en
Aparte de los dos sitios ar-

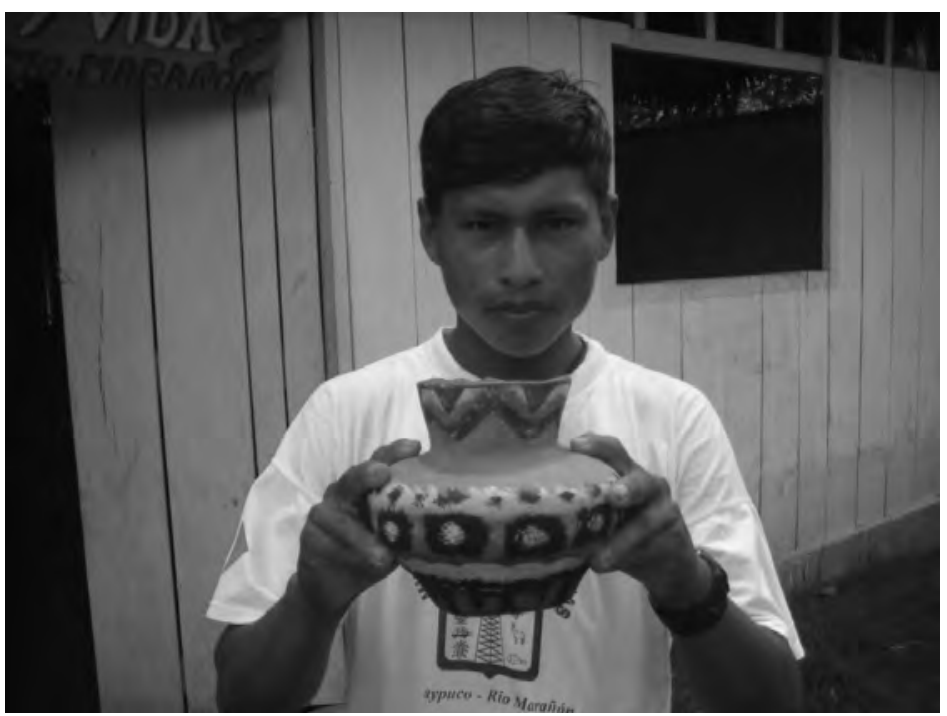


Cuninico y Maipuco, así como con otros lugares de la selva amazónica.

\section{Nuevo SAN JuAN}

Población ubicada en la intersección de los ríos Marañón y Chambira (Coordenada UTM WGS 84-Zona 18: 0520497E/9496029N). En esta localidad se registró fragmentos de cerámica muy similar a aquella observada en Cuninico: fragmentos con decoración incisa en forma de volutas así como fragmentos con engobe claro y pintura ocre (fig. 11).

\section{SAN GABRIEL}

Población a orillas del Marañón, al sureste de Nuevo San Juan, muy cerca a quebradas prove-

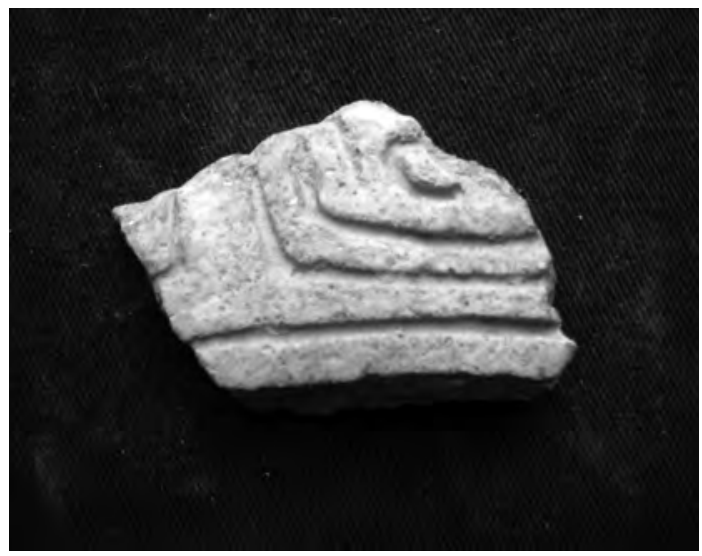

Figura 11. Fragmento de cerámica de Nuevo San Juan

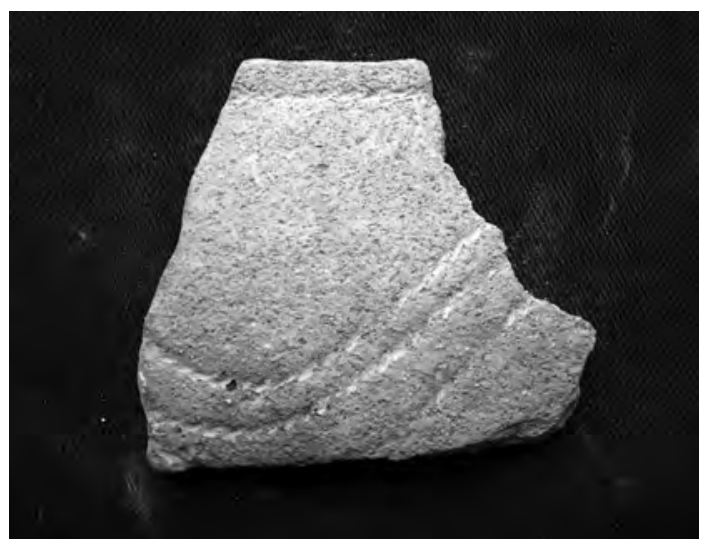

Figura 12. Fragmento de cerámica de San Gabriel. nientes del Chambira (Coordenada UTM WGS 84-Zona 18: 0522730E/9489893N). En esta localidad se observó fragmentos de cerámica alisados y decorados mediante la aplicación de cuerdas sobre arcilla fresca, decoración no registrada en otros lugares. De igual manera, se encontraron fragmentos de vasijas hechas en base a la técnica del anillado, tal como se pudo observar también en Maipuco (fig. 12).

\section{VICTORIA}

Población a orillas del río Marañón a medio camino entre San Gabriel y Huallpa Isla (Coordenada UTM WGS 84-Zona 18: 0521425E/9487240N). En este lugar se observan fragmentos de cerámica muy burda a los alrededores de Tachcacocha, así como el borde de un plato de superficie alisada y decorado con vetas de engobe crema en el borde exterior, y fragmentos de una urna o gran olla decorada con engobe crema y líneas ocre.

\section{HuALLPA ISLA}

Población a orillas del río Marañón, a medio camino entre Victoria y 18 de Julio (Coordenada UTM WGS 84-Zona 18: 0517864E/9483492N). Observamos un borde de olla que tenía el labio decorado con incisiones grandes y profundas (fig. 13).

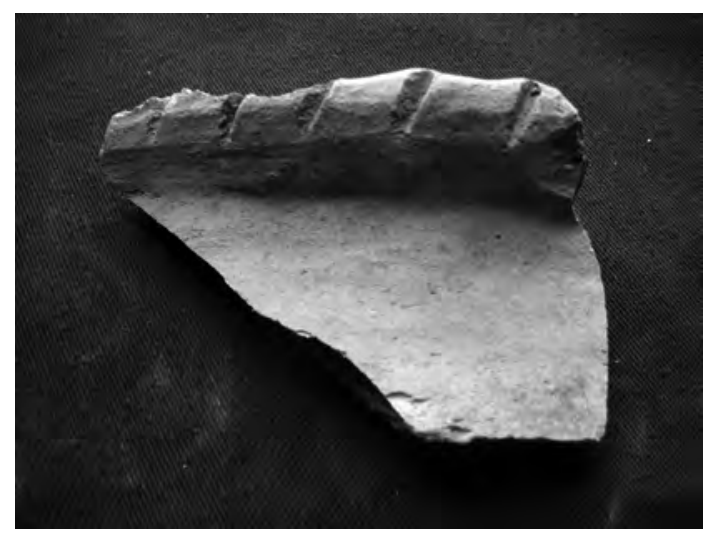

Figura 13. Fragmento de cerámica de Huallpa Isla 


\section{SAN José de SARAMURo}

Población a orillas del río Marañón, al este de Huallpa Isla. En dicha localidad se encuentra la estación más importante de Petroperú (Coordenada UTM WGS 84-Zona 18: 0504275E/9476456N) (fig. 14).

\section{Nueva Santa Rosa}

Poblado a orillas del río Marañón, a unos 25 minutos en lancha al oeste de Cuninico (Coordenada UTM WGS 84-Zona 18: 0464990E/9470746N). Observamos una pequeña botella alisada de color gris, con dos asitas que fungían de brazos y decoración punteada en el cuello de la pieza, a manera de collar. Cabe destacar que los pobladores de Santa Rosa mencionaban la existencia de una "Iglesia de los Incas" kilómetros al interior de la selva, en el lugar primigenio de la fundación del poblado, el cual fue abandonado siglos atrás debido a la peste o "veringa negra" (fig. 15).

\section{SAnta Martha}

Poblado ubicado en la parte media del Tigrillo, entre las comunidades de Pandora y Nueva Unión. En el embarcadero de la comuni-

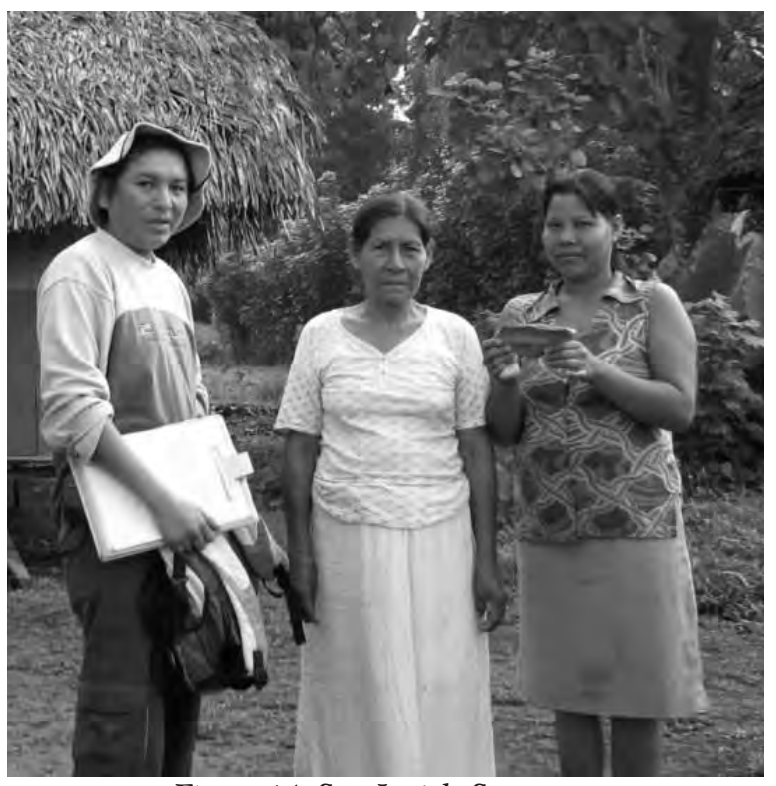

Figura 14. San José de Saramuro dad (Coordenada UTM WGS 84-Zona 18: $493467 \mathrm{E} / 9503995 \mathrm{~N}$ ), a unos 0.60 metros de profundidad, se pueden observar fragmentos de cerámica con decoración incisa y engobe rojo (figs. 16 y 17).

Nueva Angora

Poblado ubicado en la parte media del río Tigrillo, entre las comunidades de Santa Cruz de Tagual y Pandora. A 15 minutos al oeste de la comunidad se nos mostró una cabeza de figurina de arcilla (fig. 18).

Mencionaremos también algunos lugares en las orillas del Marañón o zonas circundantes en que se nos indicó la existencia de material arqueológico el cual no pudo ser confirmado:

- Santa Rosa de Aerico (quebrada de Aerico)

- 20 Millas (quebrada de Yanayacu, al interior de la Reserva de Pacaya - Samiria)

- Nueva Alianza (en el cruce las quebradas de Uritoyacu y el rio Marañón)

- Poblados de Nuevo Lima (CoordenadaUTM WGS 84-Zona 18: 0524061E/9493709N), Berlín (Coordenada UTM WGS 84Zona18: 0523516E/9485140N), 18 de Julio (Coordenada UTM WGS 84-Zona

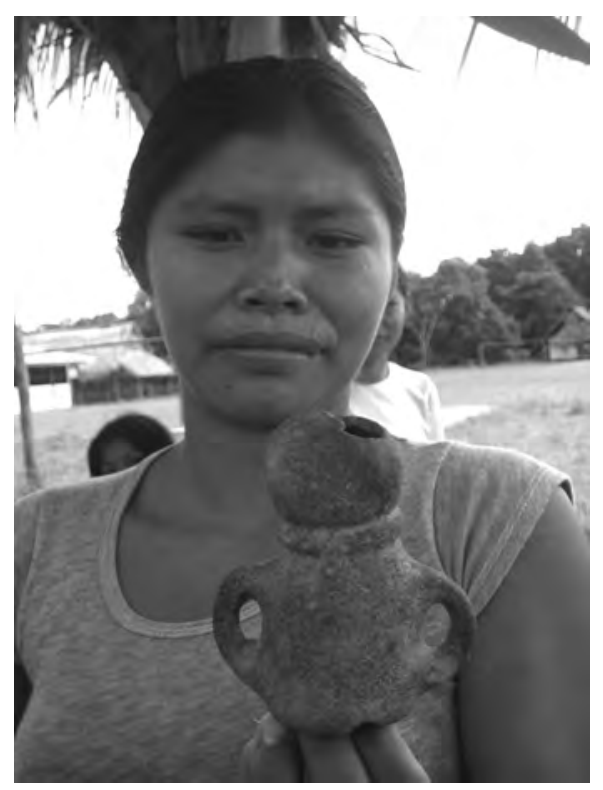

Figura 15. Vasija de Nueva Santa Rosa 
18:0515687E/9482999N), Buenos Aires (Coordenada UTM WGS 84-Zona 18: 0513846E/9480854N), Nueva Elvira (Coordenada UTM WGS 84-Zona 18: 0513437E/9479921N), San Pedro de Maipuco en la cocha de Tiwinza (Coordenada UTM WGS 84-Zona 18: 0493283E/9473628N), Nueva Esperanza en la quebrada de Sacarita (Coordenada UTM WGS 84-Zona 18: 0489354E/9467942N), Urarinas (Coordenada UTM WGS 84Zona 18: 0469545E/9470378N) y Santa Teresa (Coordenada UTM WGS 84-Zona 18: 0461788E/9469318N), todos a orillas del río Marañón.

- Santa Cruz de Tagual y Tres Fronteras (en el río Tigrillo)

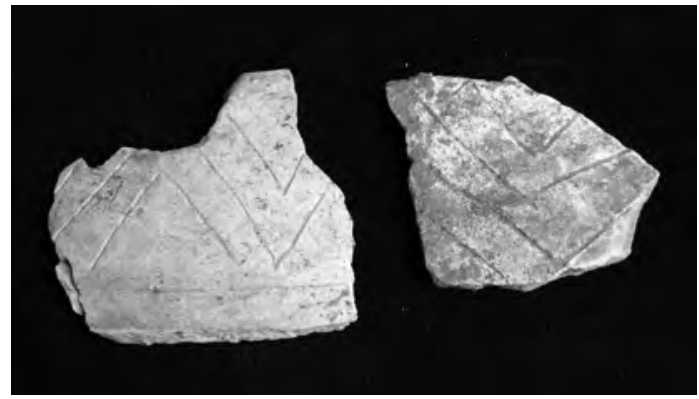

Figura 16. Fragmentos de vasijas con decoración incisa de Santa Martha.

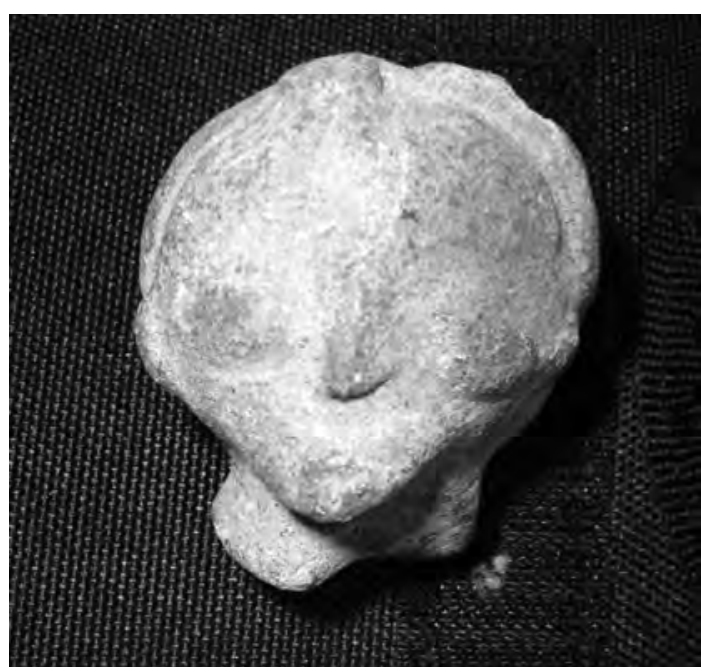

Figura 18. Cabeza de figurina hallada en Nueva Angora.
Finalmente, agregaremos aquellos sitios arqueológicos registrados por Daniel Morales (Morales, 1992) ubicados en las cuencas del río Chambira y Tigrillo al suroeste del Lote 106. Estos son:

a. Comunidad de Nueva Esperanza - río Chambira. Se ubicó nueve sitios arqueológicos dispersos en una extensión de 4 kilómetros. Se encontró fragmentos de cerámica en superficie.

b. Comunidad de San Jorge - río Siamba. Tributario del río Chambira. Se encontró un asentamiento de grandes proporciones, lejos del río. Se encontró fragmentos de cerámica en superficie.

c. Comunidad de Nuevo Angora - río Tigrillo. Se registró cuatro sitios arqueológicos en una extensión de 3 kilómetros. Se registró fragmentos de cerámica en superficie.

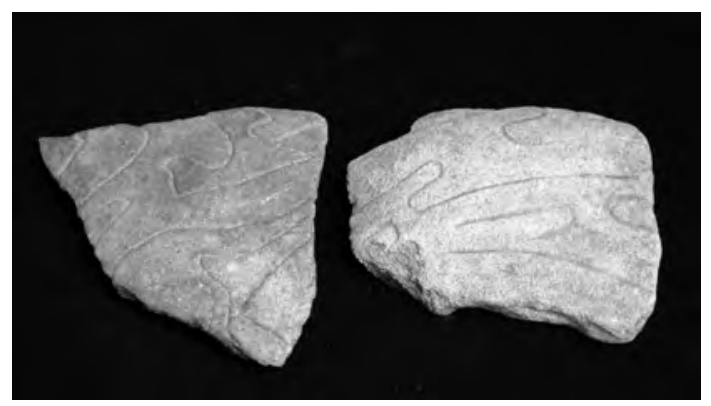

Figura 17. Fragmentos de cerámica incisos registrados en Santa Martha

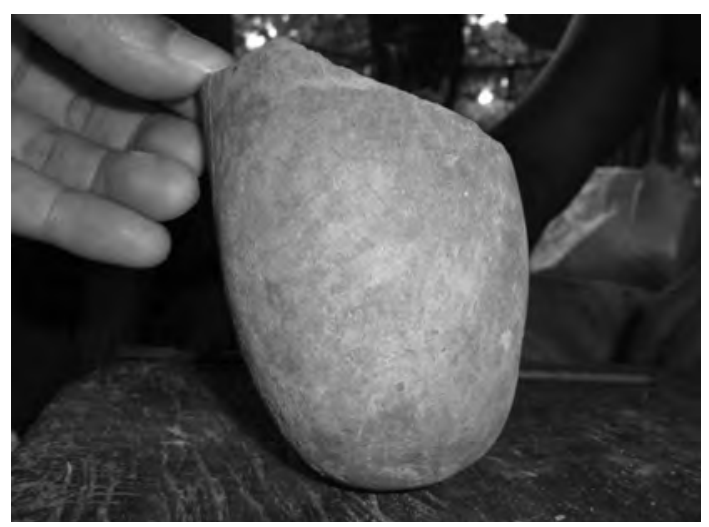

Figura 19. Ceramio de Quebrada de Lupunayo, Boca de Copal. 
Figura 20. Fragmentos de cerámica en terrenos del señor Tuy Tuy (San Juan de Pavayacu)
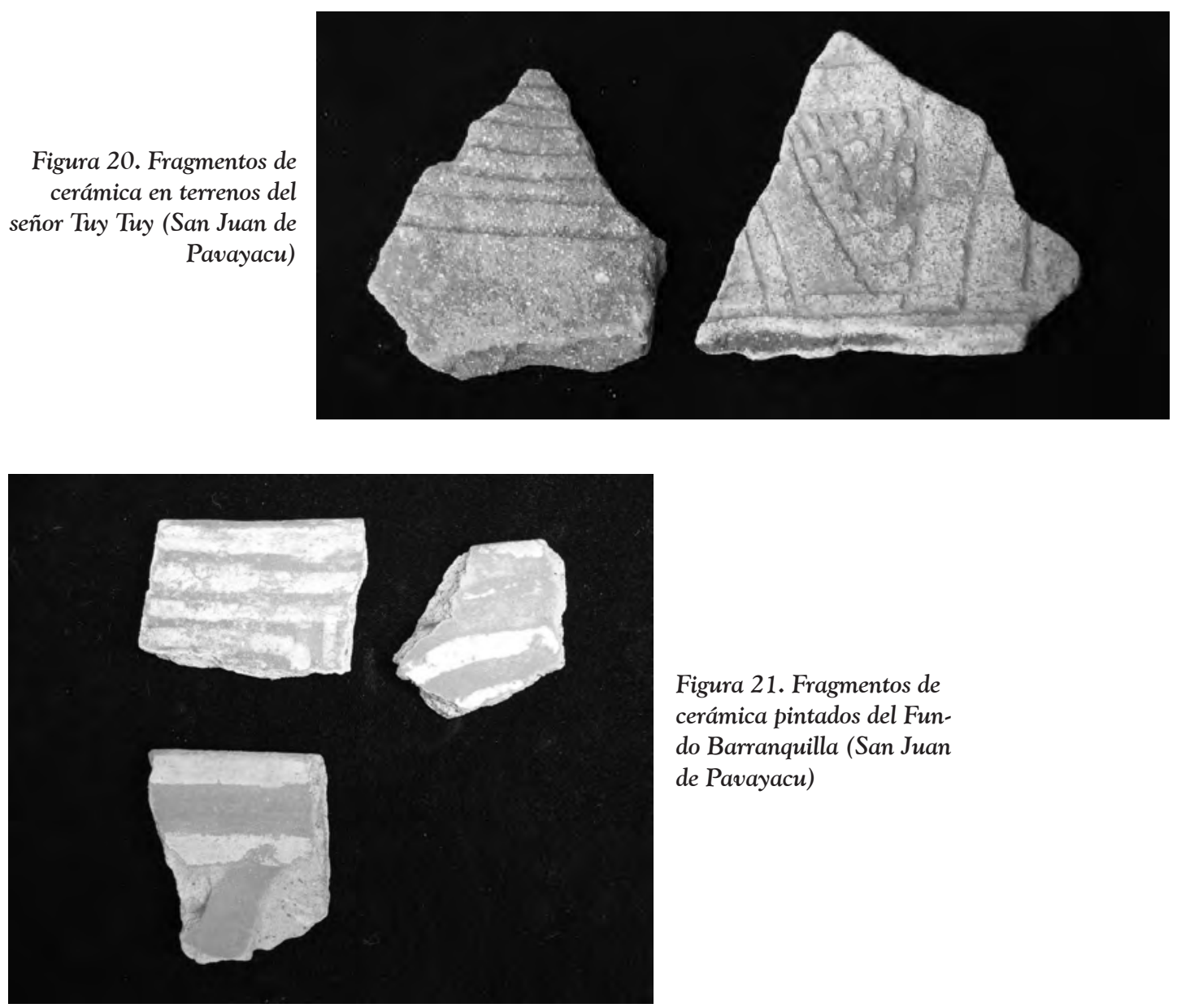

Figura 21. Fragmentos de cerámica pintados del Fundo Barranquilla (San Juan de Pavayacu)

Figura 22. Fragmentos de cerámica incisos del Fundo Barranquilla (San Juan de Pavayacu).

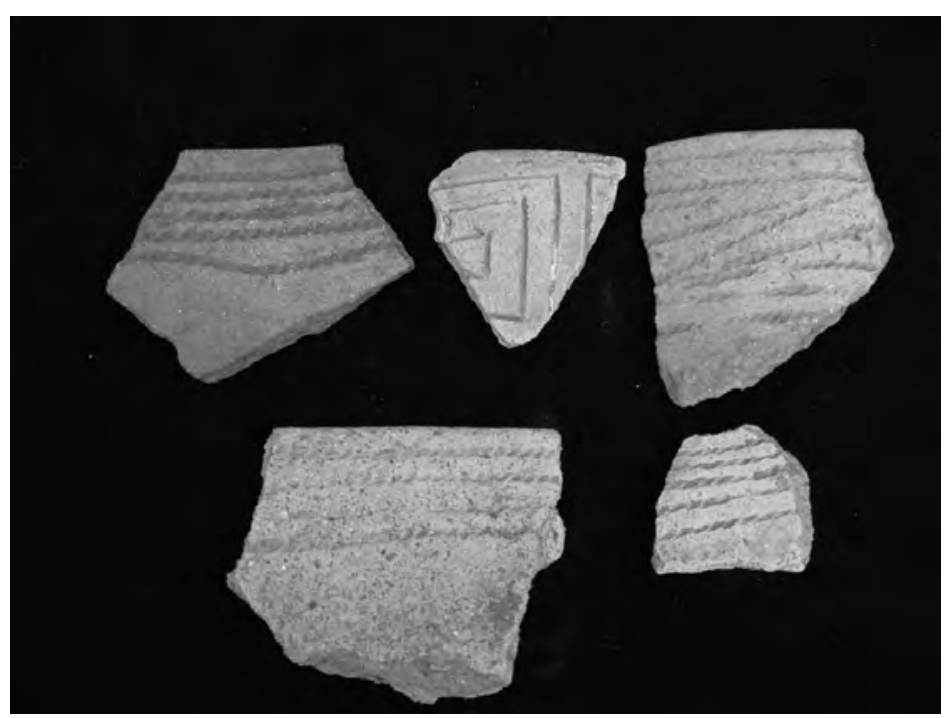




\section{Discusión}

Durante el recorrido de 105 kilómetros del curso del río Marañón, entre los poblados de Santa Teresa y Ollanta, en un área estratégica al ser un punto medio de contacto entre las vías fluviales del propio Marañón, Huallaga, Ucayali y Amazonas, se pudo observar que en las actuales poblaciones ribereñas y alrededores existen evidencias de ocupaciones anteriores, siendo las más resaltantes aquellas halladas en los poblados de Cuninico y Maipuco, lugares de intersección entre el Marañón y quebradas navegables que son fuentes de materias primas. En ambos sitios, se trata de dos contextos típicos de la arqueología de la selva baja del Perú: el primero, un lugar totalmente inundado y sólo evidente durante las mermas estacionales del río y el segundo, destruido por la construcción del estadio del poblado. Pese a ello, el presente trabajo ha podido recopilar importante información que permite plantear las primeras hipótesis acerca de la historia prehispánica de esta parte del Marañón en sus épocas tardías.

En primer lugar, pareciera existir dos estilos contemporáneos claramente diferenciados, aquellos observados en Cuninico y en Maipuco, que pueden corresponder a diferencias funcionales; mientras que en Cuninico los fragmentos de cerámica decorados son prácticamente toda la muestra, en Maipuco era totalmente lo contrario, sumándose a ello una importante cantidad de piruros de arcilla. Resulta necesario comparar estos materiales con los antes excavados en otras regiones colindantes y con trabajos de campo en las localidades en mención. En segundo lugar, es interesante observar que las muestras registradas en otras poblaciones de la zona son muy similares, tanto a aquellas de Cuninico como -y sobre todo- a las de Maipuco. Finalmente, fue notable ver que muchas de las formas y decoración de la cerámica arqueológica que se pudo registrar, se mantienen en la producción de ceramios de la zona sobre todo en la quebrada del río Chambira, en donde la etnia Urarinas mantiene sus tradiciones artesanas prácticamente intactas.

\section{Anexo: Hallazgos en el Río Corrientes}

Como parte de los trabajos de evaluación arqueológica en el Lote 106, se hizo el recorrido de casi 95 kilómetros en las dos márgenes del río Corrientes, particularmente de las zonas en que el Corrientes se une con el río Copal y la quebrada de Pavayacu. El área recorrida estaba comprendida entre las localidades de Boca de Copal y Cuchara, territorios de las etnias ashuar y kishua.

Durante la evaluación de la zona, se pudo registrar restos arqueológicos en el mismo poblado de Boca de Copal (Coordenada UTM WGS 84-Zona 18: 462784.00E/9589562.00N), en los cruces del Corrientes con el río Copal, en la quebrada de Lupunayo en la margen izquierda del Corrientes (Coordenada UTM WGS 84-Zona 18: 465858E/9588172N) (fig. 19) y finalmente en el poblado de San Juan de Pavayacu, exactamente en los terrenos del señor Gonzalo Tuy Tuy (Coordenada UTM WGS 84-Zona 18: 529399E/9593166N) (fig. 20) y en Fundo Barranquilla (Coordenada WGS 84Zona 18: 531192E/9592640N) (figs. 21 y 22). Los materiales del Corrientes eran muy similares a algunos de los fragmentos observados tanto en Cuninico como en Maipuco, así como en otras localidades del Marañón, a excepción de algunos fragmentos incisos aparentemente más tempranos, los cuales podrían ser del periodo Formativo.

\section{Agradecimientos}

Nuestro agradecimiento, en primer lugar, a Petrolífera Petroleum del Perú y a PGS Onshore por su apoyo logístico para realizar los trabajos de campo; nuestro agradecimiento especial a Carlos Monges, José Miguel Rossaza, Cesar Monges, Roberto Muñoz y José Veliz. A las autoridades de todas las localidades visitadas, a la dotación policial de Maipuco y a Isabel Jiménez, arqueóloga del INC de Iquitos. 


\section{Bibliografía}

Deboer, Warren

1981 Longevidad Cerámica e Interpretación arqueológica: un ejemplo del alto Ucayali. En: Amazonía Peruana Vol. IV (7): 65-78.

Fung, Rosa

1981 Notas y comentarios sobre el sitio de Valencia en el Río Corrientes. En: Amazonía Peruana Vol. IV (7): 99. 138.

Guffroy, Jean.

2006 El Horizonte corrugado: correlaciones estilísticas y culturales. En: Bulletin del I'Institut Francais d'Études Andines. Tomo 35(3) 347-359.

Lennon, Thomas, Warren Church y Miguel Cornejo.

1989 Investigaciones arqueológicas en el Parque Nacional Río Abiseo San Martín. En: Boletín de Lima $\mathrm{N}^{\circ} 62$ : 43-56.

Latharp, Donald

1963 Investigación de las relaciones culturales entre la montaña peruana y las altas civilizaciones de los andes centrales. En: Revista del Museo Nacional Tomo XXXII: 197-202.

1970 The Upper Amazon. London:bThames and Hudson.

Meggers, Betty

1981 La Reconstrucción de la Pre-Historia amazónica. En: Amazonía Peruana Vol. IV (7): 15-30.

Morales, Daniel

1992 Chambira: Alfareros tempranos de la Amazonía peruana. En: Revista de Estudios de Arqueología Peruana, p. 149. 157.

Morales, Daniel y Eva Ruiz Aguilar

2004 El Problema de la conservación de restos arqueológicos en la Amazonia Peruana: El caso del sitio "El Zapotal" en la Reserva Nacional Pacaya - Samiria. En: Supay, Revista de Hu- manidades y Ciencias del Hombre de la UNFV. Año 6, Numero 5: 111-132. Lima

Myers, Thomas y Bartholomew Dean

1999 Cerámica Prehispánica del río Chambira, Loreto. En: Amazonía Peruana, Tomo XIII N² 26: 255-288.

Myers, Thomas

1976 Isolation and ceramic change: a case from the Ucayali River, Peru. En: World Archaeology 7 (3): 333-351.

1981a Ceramics from the Hacienda Tarapoto, department of San Martín, Perú. En: Nawpa Pacha 19: 155-66.

1981b Hacia la Reconstrucción de los Patrones Pre-Históricos Comunales en la Hoya Amazónica. En: Amazonía Peruana Vol. IV (7): 31-64.

Olivera, Quirino

1998 Evidencias arqueológicas del Periodo Formativo en la cuenca baja del río Utcubamba y Chinchipe. En: Boletín de Arqueología PUCP, N²: 105-112.

Ravines, Roger

1981 Yacimientos Arqueológicos de la región Nororiental del Perú. En: Amazonía Peruana Vol. IV (7): 139-176.

Rivas Panduro, Santiago

2003 Los asentamientos prehispánicos de la cuenca del río Cachiyacu. Instituto Cultural Rvna.

Rivas Panduro, Santiago y Thomas Myers

2004 Ocupación arqueológica en Oran. Río Amazonas, Loreto-Perú. En: Supay, Revista de Humanidades y Ciencias del Hombre de la UNFV. Año 6, Numero 5 p: 133-180. Lima

Shady, Solís

1979 El Complejo Bagua y el sistema de establecimientos durante el Formativo en la sierra norte del Perú. En: Ñawpa Pacha $\mathrm{N}^{\circ}$ 17: 109-142. 